\title{
PREDICTING STORM-TRIGGERED LANDSLIDES
}

\author{
by Diandong Ren, Rong Fu, Lance M. Leslie, and Robert E. Dickinson
}

\section{An advanced numerical modeling system projects rain-triggered landslides in a warming climate.}

W ith the continued growth and expansion of the human population, rain-triggered shallow landslides often result in loss of life and significant economic cost. From an ecological viewpoint, landslides are an important factor in desertification over mountainous regions, because they are an effective means of transferring biomass from live to dead respiring pools. Fatalities from landslides that followed the 2008 Wenchuan earthquake (Ren

AFFILIATIONS: REN*_Department of Geological Sciences, The University of Texas at Austin, Austin, Texas; Fu AND DICKENSONDepartment of Geological Sciences, The University of Texas at Austin, Austin, Texas; LesLIE-School of Meteorology, College of Atmospheric and Geographic Sciences, University of Oklahoma, Norman, Oklahoma, and Australian Sustainable Development Institute, Curtin University, Perth, Western Australia, Australia *CURRENT AFFILIATION: Australian Sustainable Development Institute, Curtin University of Technology, Bentley, Perth, Western Australia

CORRESPONDING AUTHOR: Diandong Ren, Australian Sustainable Development Institute, Curtin University of Technology, GPO Box U1987 Perth, Western Australia 6845 E-mail: dd_ren@jsg.utexas.edu

The abstract for this article can be found in this issue, following the table of contents.

DOI:10.1175/2010BAMS3017.I

A supplement to this article is available online (I0.1175/2010BAMS3017.2)

In final form 26 July 2010

()ㅣㄴ American Meteorological Society et al. 2009; Stone 2009) demonstrate how increasing populations in high-risk settings have enhanced the threat of this ubiquitous and costly natural hazard and accordingly have increased the urgency to develop and install effective early prediction and warning systems.

Landslides are movements of the Earth's surface, illustrating many of the interconnected processes that influence landscape stability (Bhandari 1988; Dietrich and Perron 2006; van Asch et al. 2007). In principle, any factors assisting gravitational stress overcoming resistive strength of the slope material can trigger landslides. For example, increased surface loading by trees, hailstorms, reduced material strength by elevated water content or intense frictional heating, and even Perseid meteor showers all contribute to slope instability. Where and when landslides occur depends on local topography, geological composition, forest cover, soil water content, precipitation morphology, and seismic activity. For the majority of landslides, it is agreed upon that rainfall and earthquakes are the main triggers and that the former is far more frequent than the latter (e.g., Schuster and Highland 2001; Restrepo et al. 2008). However, when the gravitational driving stress and the resistive stress are in "perfect balance," even small perturbations, such as atmospheric tidal fluctuations, may cause systematic slope movement (Schulz et al. 2009). The focus of this study is on storm-triggered shallow landslides.

Landslides occur irregularly, and future research is concerned with more accurate predictions about 
their timing (when), location (where), and size (how big they will be), and with developing procedures that convey risk and warnings to the public to mitigate damages to infrastructure and ecosystems. Such an effort is critical, particularly in anticipating the effects of climate change on areas prone to instability. Empirical and descriptive landslide models (Caine 1980; Cannon and Ellen 1985; Sirangelo and Versace 1996; Godt et al. 2006) have contributed tremendously to the public awareness of the hazard and accumulated valuable experience on identifying important causal factors.

Caine (1980) proposed the seminal rainfall intensityduration threshold line (above which shallow landslides may occur), based on 73 landslides worldwide on natural slopes. Godt et al. (2006) argued that landslidetriggering rainfall must be considered in terms of its relationship with antecedent rainfall. For example, a heavy rainfall event within a dry period is not likely to trigger shallow landslides, whereas the opposite is true for lighter rainfall within a wet period. Because it directly affects soil moisture conditions, Godt et al. (2006) correctly claim that antecedent rainfall must be included in the empirical model's assessment of a rainfall's potential in causing a landslide. Godt et al.'s (2006) approach is a significant improvement over Caine's (1980) seminal rainfall intensity-duration threshold line approach. Hong and Adler (2008) further adapted the empirical rainfall intensity-duration thresholds technique for global assessment of stormtriggered landslide hazards by using remotely sensed precipitation rather than ground-based observations. Remotely sensed precipitation has near-global coverage and is available almost in real time. Hong and Adler's (2008) study is thus another significant improvement of the traditional empirical intensity-duration threshold method. Recent empirical methods also compile many soil hydrological parameters by using water-balance models with little physical basis but are convenient for estimating soil moisture conditions. For example, Godt et al. (2006) uses a detailed assessment of rainfall-triggering conditions, hill slope hydrologic properties, soil mechanical properties, and slope stability analyses.

A synthetic consideration of preparatory and triggering factors, however, demands a comprehensive modeling of the physical processes involved in landslides (Costa 1984; Iverson 1997; Casadei et al. 2003; van Asch et al. 2007, and references therein). The overview by Iverson (1997) offers criteria for dynamic landslide models, such as a model should simulate the full start-movement-spread-cessation cycle of the detached material and should have the ability to describe a wide spectrum of flows. Along these lines, there are physically based slope stability models to simulate the transient dynamical response of pore pressure to spatiotemporal variability of rainfall [e.g., Transient Rainfall Infiltration and Gridbased Regional Slope-Stability Analysis (TRIGRS); Baum et al. 2008]; commercially available numerical modeling codes for geotechnical analysis of soil, rock, and structural support in three dimensions [e.g., Fast Lagrangian Analysis of Continua in Three Dimensions (FLAC3D), www.itascacg.com/flac3d]; and fully three-dimensional, full Navier-Stokes, and multirheological modeling systems, such as the Scalable and Extensible Geofluid Model of the Environment (SEGMENT; Ren et al. 2008, 2010, 2011).

\section{THE UNIQUENESS OF SEGMENT. SEGMENT}

is a recently developed and thoroughly tested mechanistic (process based) modeling system for monitoring and predicting storm-triggered landslides and their ecosystem implications. It is a tool for investigating the roles of triggering factors in sliding, and it offers a unique opportunity for regional-scale assessment. In SEGMENT, landslides are simulated using a full three-dimensional Navier-Stokes solver. This is necessary because, as a mechanism for releasing unevenly concentrated stress, landslide occurrence at one specific location affects the stability of adjacent areas. "Legacy effects" (Casadei et al. 2003) is one example. Although tending to miss landslides that have no historical precedent, many empirical and theoretical procedures at present tend to overpredict the area that may fail in a given rainstorm (Casadei et al. 2003; Wooten et al. 2008; Y. Hong and Z. Liao 2010 , personal communication). The overestimation tendency occurs because many empirical models build indices based on historical events. However, the occurrence of a slide, through releasing the stress buildup, makes the surrounding area more stable and less likely to experience future sliding.

There are situations when previous landslides do assist subsequent landslides. Individual landslides transform limited amounts of potential energy into heat. However, in the case of earthquakes, the heat released by thousands of simultaneous landslides is significant enough to interact with the local convection process. The intense storms that follow may cause widespread landslides in the same area. This is vividly illustrated by the Wenchuan earthquake, which induced more than 5000 landslides and 3600 rock falls. The massive amount of potential energy was transferred into heat and enhanced local convection. The following storms incurred $\sim 358$ debris flows and 
resulted in a direct economic loss of nearly $\$ 60$ billion (U.S. dollars). SEGMENT thus simultaneously solves the thermal equation, the dynamic equations, and the surface kinematic (continuity) equations.

SEGMENT, because it synthetically simulates landslides over a continuous regional area, can in principle minimize the false-alarm tendency of most empirical procedures. Against the 2007 wildfireburn background, using the observed precipitation, SEGMENT simulated the landslide cases during the year 2008 for a region with documented landslides (Ren et al. 2011). It has proven to be able to identify landslide locations but needs improvement in simulating the exact timing of landslide occurrence. Through improving the land surface scheme, it is believed that the model skill can be systematically improved. Inserting the landslide model component into a scalable and extensible system (Fig. 1) also makes implementation of newly identified physical processes more convenient. We illustrate this by describing how SEGMENT identifies rainfall intensity as a critical factor affecting slope stability.

Why is precipitation intensity so critical? Many studies emphasize the importance of precipitation intensity, instead of the rainfall total, as the key for triggering landslides (Cannon et al. 2003; Cannon and Gartner 2005). It is clear that, for more intense precipitation, a relatively larger proportion of rainfall goes into surface runoff (Fig. 2a). That the precipitation intensity is vital for triggering landslides is believed to be because of the surface runoff contribution to "progressive bulking" of the entrained ground material. This is a valid argument for vegetated surfaces, especially those affected by fires. For most slopes, however, the detachment of a soil slab by Horton overland flow may be quite limited. A ubiquitous feature of soil slopes is that they have cracks or crevasses. In studying a slope with repeated landslide history, the Yangjiashan creeping slope of China (located at $29^{\circ} 50^{\prime} \mathrm{N}, 109^{\circ} 14^{\prime} \mathrm{E}$; Ren et al. 2010), it is revealed that the existence of macropores channels runoff directly to the shear zone granular material. This is a lubricating effect contributing to basal sliding and an enhanced sliding speed for the overlying slab. Detailed geological surveys are conducted for this area because important infrastructures are in danger. A mask of surface scarps and cracks are provided on a 20-m grid resolution. In addition, boreholes are drilled to provide the vertical profile of the sliding slab. Yangjiashan creeping slope also is close to the Enshi synoptic observing (SYNOP) station, so we have observed meteorological parameters to drive the landslide models.

For the three historical events of 1960, 1980, and 1998, TRIGRS and FLAC3D both simulated sliding layer shallower than reality. With the same in situ meteorological forcing, SEGMENT is the only model that has provided sliding scars comparable with observations. SEGMENT also satisfactorily simulates the creeping rates at all depths of the borehole measurements (Ren et al. 2010). Aside from the differences in numerical formulation, SEGMENT is the only landslide model reinforced by a land surface scheme that parameterizes the drainage of macropores and interconnected underground channels. The model simulations clearly indicate that, in the presence of macropores or crevasses, it is unnecessary for the entire soil slab to be saturated to trigger landslidesonly enough water to effectively channel into the shear zone granular material suffices. This explains why storm intensity is found to be more important than rainfall total in triggering landslides.

To underpin the above assertion, we examine the effects of macropores using idealized geometric

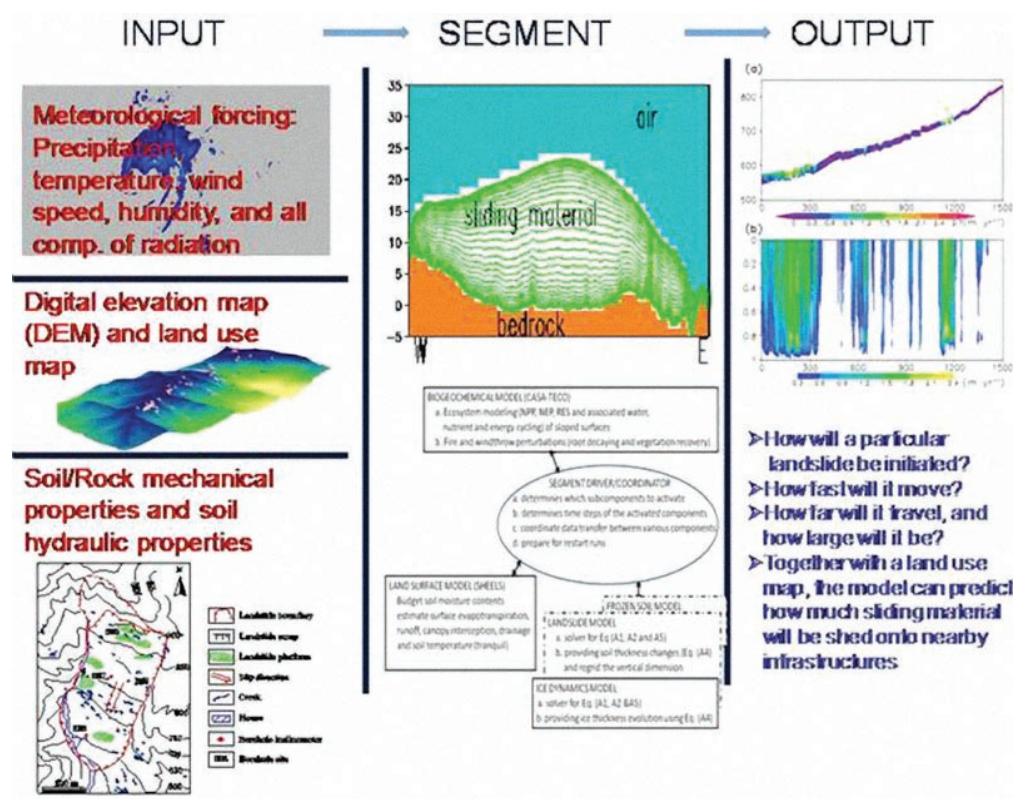

FIG. I. Conceptual framework for SEGMENT landslide for the projection of storm-induced landslides. The numerical techniques, model physics, and input and output parameters are described in Ren et al. (2010). 
setting (Fig. 2). Rainfall totals and other parameters being equal, one set assumes a more intense rainfall (200 mm day ${ }^{-1}$ lasted for $3 \mathrm{~h}$; Fig. 2a) and the other assumes a milder rainfall $\left(30 \mathrm{~mm} \mathrm{day}^{-1}\right.$ for $20 \mathrm{~h}$; Fig. $2 \mathrm{~b}$ ). The resulting soil moisture condition and the flow structure are schematically shown in Fig. 2. The more intense rainfall generates widespread surface ponding, and some of the waters are channeled to the granular shear zone. The strain rates (shears) are largest within this granular zone, and a maximum velocity is reached at the top of this thin granular layer present above the unfractured bedrock. Flow magnitude is almost constant until reaching the near-surface saturated soil zone. The less intense rainfall case saturates a deeper surface soil layer. Flows are only significant within this surface layer and generally cannot exceed $1.3 \mathrm{~mm}$ $\mathrm{s}^{-1}$. Thus, as measured by the maximum achievable flow speed, landslides caused by intense rainfall pose larger damage potential. The shear zone of Yangjiashan slope lies $50 \mathrm{~m}$ underneath the surface, whereas rainfall usually saturates a surface soil slab less than a meter. Thus, landslides triggered by intense storms usually involve deeper scarps. Including macropore in the land surface scheme

a)

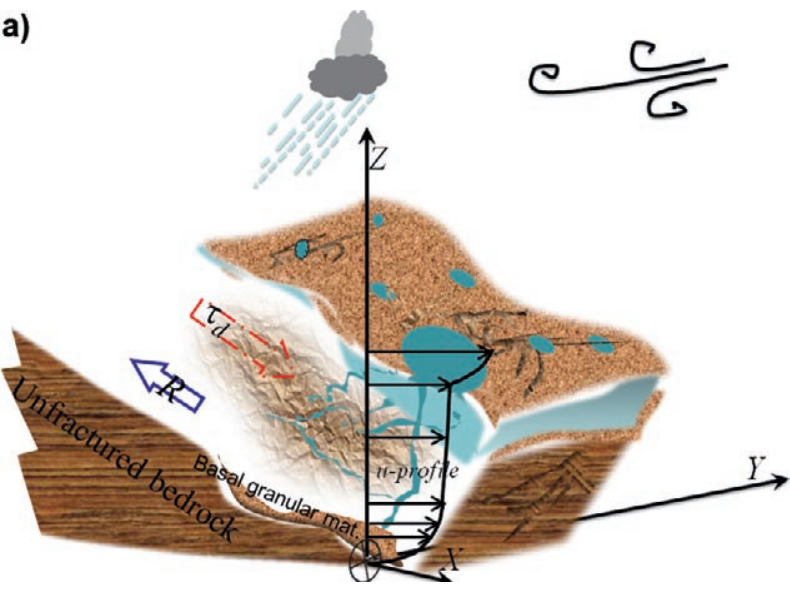

b)

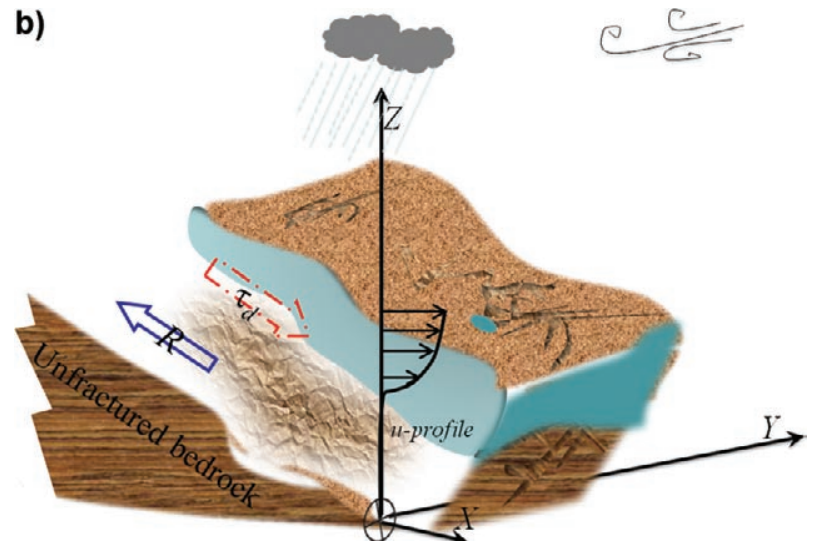

to describe the soil moisture distribution may also assist in predicting the specific size and location of landslides for a given precipitation event.

Are plants ready for storm-triggered landslides? The ecosystem consequences of landslides need to be addressed from an evolutionary point of view. Windthrow, forest fires, and landslides burial of vegetation are quite different phenomena. They all indicate the vulnerability of terrestrial ecosystem to extreme meteorological conditions, reflecting climate modulations on ecosystem (Holdridge 1947). They also are related to the water cycle of the climate system. To plants, infrequent windthrow and landslides are life threatening. Larger canopy size may be advantageous for competing light and utilizing $\mathrm{CO}_{2}$ but apparently it is a liability as to wind stress load (or ice load during ice storms), which contributes to stem break and also landslides for vegetated slopes. The same rule holds for stems. In this sense, plants need to make decisions on how much new production to invest in defense against extreme events against how much is invested into the persistent competition for nutrients to achieve the ultimate goal of maximum growth and reproduction. Comparing a single plant to an ecosystem is much like comparing a company to a human society. It evaluates the biochemical investment's gain, within its lifespan. When maintenance cost for extra coarse roots to cope with the severe landslides that may not occur during its life

Fig. 2. Vertical cross section of soil mantle with underlain fractured rocks. The circular blue blobs are surface ponding water. The blue shading indicates soil moisture fronts. The $U$ velocity profiles are shown as black curves. The left arrow indicates resistive stress $R$ and the right arrow indicates driving stress $\tau_{d^{\circ}}$ (a),(b) The same precipitation amount and different intensity. For (a), because it experiences more intense precipitation, a larger proportion goes into surface runoff and ponding. The ponding water is drained through macropores directly to the shear zone granular material ("basal granular material"). This is a lubricating effect and enhances sliding. The velocity increases from zero at the interface with the unfractured bedrock to a certain amount at the upper boundary of the underlain granular layer. This velocity magnitude is kept almost constant upward until reaching the near-surface saturated soil layer. For (b), lower precipitation intensity gives the soil enough time to infiltrate. The moisture is more evenly distributed and saturates the soil mantle to a deeper depth than (a). However, the shear zone granular material is not moistened, and the resulting flow is limited to the near-surface saturated soil layer; thus, a much shallower sliding layer is involved. 
expectancy outweighs the advantages gained in competing for resources if invested in leaves or fine roots, it may not take action to reinforce coarse roots. Plants making an unwise decision have a disadvantage in the competence of above-ground resources and consequently may face the fate of extinction.

Natural selection has "taught" existing species to have strong enough stems and roots to cope with windthrows and landslides of the natural recurrence frequency. Are they ready for a future warming climate with an apparent human fingerprint? This is a valid concern because, unlike natural variability, human-induced climate changes are likely to have stronger trends. A broad consensus is that anthropogenic climate warming this century will develop a signal far above the natural variability background noise level (Hansen et al. 2006). The mean global warming likely manifests itself over a range of spatial and temporal scales, including altering the frequency and magnitude of extreme events (White et al. 2006; Meehl and Tebaldi 2004; Zwiers and Kharin 1998; Peterson and Manton 2008). With a state-of-theart ecological submodel, SEGMENT is well positioned to investigate the ecological consequences of landslides.

SEGMENT treats not just the failure of Earth materials but also the deformation and movement cycle from initiation to cessation. With a land-use map, it can be used to estimate sediments/nutrients lost to water bodies or sliding material shed onto infrastructure. Specifically, for coastal regions, the seaward runoff of sediments and nutrients can be estimated. It thus estimates the ecosystem consequences of landslides. The following discussions and assertions are based primarily on this modeling system.

PREDICTION FOR A REGIONAL AREA OF SOUTHERN CALIFORNIA FOR THE UPCOMING 10 YEARS. What can we say about changes in storm-triggered landslides on 50-yr (or longer) time scales when we cannot predict rainfall next week? On one hand, the overall climate response of the precipitation to the increasing atmospheric concentrations of greenhouse gases may be proven predictable by current global coupled ocean-atmosphere climate models (CGCMs; Allen and Ingram 2002, and references therein). On the other hand, only very heavy or extreme precipitation triggers landslides (Iverson 2000). Although CGCMs are unable to project a specific storm's location and timing, they can provide a statistically correct rainfall scenario for the region of interest. For infrastructure construction, exact timing of landslides is of secondary importance to occurrence frequency and future locations.

To project the landslide events for the Southern California region $\left(34.09^{\circ}-34.25^{\circ} \mathrm{N} ; 118.25^{\circ}-116.8^{\circ} \mathrm{W}\right)$, SEGMENT is driven by the Community Climate System Model, version 3 (CCSM3; Collins et al. 2006), a coupled climate model of relatively high horizontal resolution of $\sim 1.4^{\circ}$ latitude $\times \sim 1.4^{\circ}$ longitude. CCSM3 simulated atmospheric parameters under a medium future greenhouse gas emissions scenario, the Special Report on Emission Scenarios (SRES) A1B (Nakicenovic and Swart 2000). SRES A1B is one of three nonmitigated Intergovernmental Panel on Climate Change (IPCC) - B1 (low rate of emission: 550 ppmv $\mathrm{CO}_{2}$ concentration by 2100); $\mathrm{A} 1 \mathrm{~B}$ (medium rate of emission: $720 \mathrm{ppmv} \mathrm{CO}_{2}$ concentration by 2100); and A2 (high rate of emission: $850 \mathrm{ppmv} \mathrm{CO}_{2}$ concentration by 2100)-emission scenarios. The A1B scenario foresees a world characterized by low population growth, very high gross domestic product (GDP) growth, very high energy use, low land-use changes, medium resource availability, and rapid introduction of new and efficient technologies. A1B thus reflects the most recent trends in the driving forces for emissions and hence is a plausible future reality.

As illustrated in Fig. 1, SEGMENT is a 3D dynamical system that requires detailed digital elevation data, soil/rock mechanical properties, and meteorological data to be able to integrate forward in time. For performing susceptibility analyses, using coarse meteorological data, such as from CGCMs, might suffice. However, for point accuracy in predicting a slope's stability, very high-resolution (spatial and temporal) precipitation data from observations or more likely from numerical weather prediction models are required to drive the landslide model. In the following experiments, we linearly downscale the CGCM-provided meteorological forcing to a highresolution digital elevation map.

To give the model components sufficient time to spin up, the time stepping starts from the year 1980 until 2020. Figure 3 indicates the landslides that may occur between 2010 and 2020. Because the atmospheric conditions are provided by a climate model, we here refrain from discussing the exact timing of the events and focus on the geometry features and flow characteristics. The numbers in the box are the landslides that involve more than $10^{5} \mathrm{~m}^{3}$ of sliding material (i.e., large landslides). The area surrounding San Bernadino generally has shallow scars, whereas those due south of the San Gabriel Range (north of 


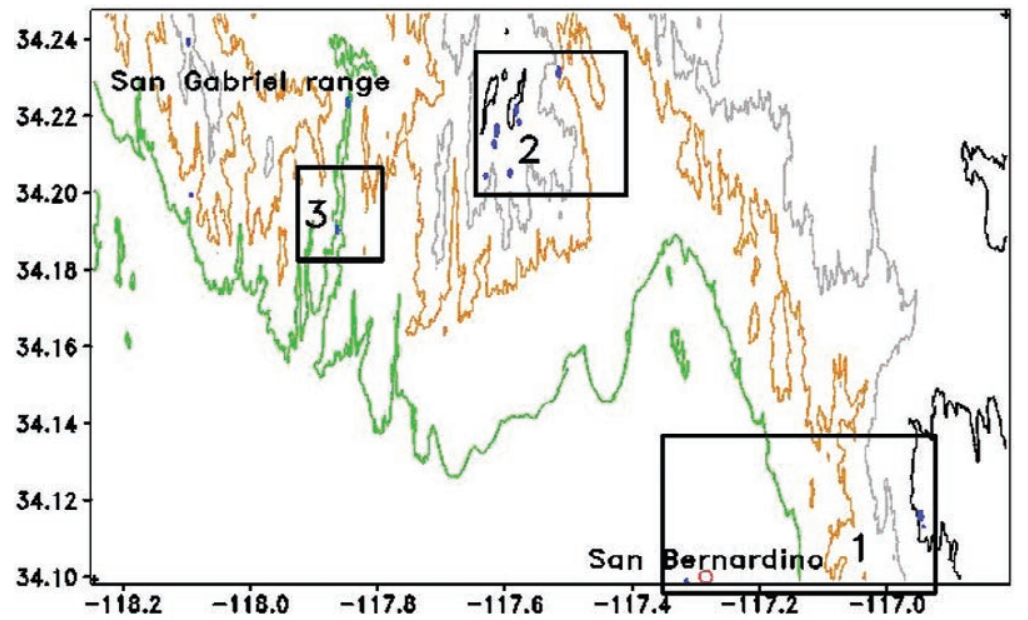

Monterey Park

$\circ$

FIG. 3. The SEGMENT projection of storm-triggered landslides in the San Bernadino area, Southern California. The atmospheric parameters are provided by the CCSM3 under the SRES AIB scenario. The numbers in the box are the slides that involve more than $10^{5} \mathrm{~m}^{3}$ sliding material. The blue specks indicate the landslide locations. The elevation contours are labeled for 500 (green), 1000 (brown), I500 (gray), and 2500 m (black). In the Program for Climate Model Diagnosis and Intercomparison (PCMDI) Coupled Model Intercomparison Project (CMIP), model simulations of the climate of the twentieth century are from an experiment called the Twentieth-Century Climate in Coupled Models (20C3M) runs for simulating present-day atmospheric conditions. The simulations of the twentieth and twenty-first centuries (SRES AIB) allow us to examine the precipitation morphological changes. the last 30 years is roughly 3 times that for the past 100 years as a whole, and it is expected that global temperature will continue to rise by between $1.4^{\circ}$ and $5.8^{\circ} \mathrm{C}$ by 2100 because of the emission of greenhouse gases (Solomon et al. 2007). The consensus view of scientists is that higher temperatures may lead to a greater proportion of intense precipitation events (Karl and Trenberth 2003; Solomon et al. 2007; NRC 2002; Kharin and Zwiers 2005; Semenov and Bengtsson 2002; Groisman et al. 2004). For most climate zones, increases in extreme precipitations are a robust constraint on which climate models have already converged (O'Gorman and Schneider 2009). It is an important scientific question whether there are changes in storm-triggered landslides in a warming climate.

All known physics considered, the CGCMs are well positioned to answer the question of whether increased temperatures cause increases in precipitation intensity and amount. Climate prediction is concerned with quantifying general
Monterey Park) leave deeper scars, often depleting the soil mantle. The western side of the valley (center of the plot) has a far higher occurrence rate and the slides are generally of smaller scale, because only 2 out of 31 scars fall into the large category. In situ measurements of geometry features of a landslide scars are scarce. The number of recurrences is only a highly averaged representation. However, realization of the projections in the upcoming 10 years would serve as a rigorous verification of SEGMENT. For other scenarios, we find that the geographic pattern for large landslides is insensitive to the degree of warming. However, the amount of sliding material involved does scale with warming: scars are smaller under the $\mathrm{B} 1$ scenario forcing than for $\mathrm{A} 2$ and $\mathrm{A} 1 \mathrm{~B}$, whereas the last two are similar.

\section{POSSIBLE WARMING CLIMATE IMPACTS ON STORM-TRIGGERED LANDSLIDES. Sci-}

entific data suggest that Earth's climate is changing at an unprecedented rate, with instrumental records showing that during the last century the global temperature rose by about $0.6^{\circ} \mathrm{C}$. The warming trend for trends and not with accurate prediction of specific storm events. This does not devalue the CGCM projections because, for many purposes (e.g., infrastructure construction), we are not interested in the exact timing of a mudslide and we only are required to know the time frame of its recurrence. The CGCMs, because of their limited horizontal resolution, are not expected to resolve individual precipitation events. A reasonable use of CGCM's projection of precipitation would be for regions with coherent precipitation features: for example, monsoon and Mediterranean climate regions. That the signals are strong in these climate zones is probably due to, at least in part, the differential warming in land areas relative to the oceans. We here select two areas of interest, located in the Asian monsoon area of China (point A in Fig. 4) and a characteristic Mediterranean climate in Southern California (point B in Fig. 4).

PRECIPITATION. Precipitation morphological changes relevant to storm-triggered landslides. Unlike normal precipitation events with life spans of less than a day, extreme precipitation events, with total 
amounts greater than $500 \mathrm{~mm}$ for the Asian monsoon region or $70 \mathrm{~mm}$ in the Southern California region, are usually distributed into groups of consecutive days. Inset A of Fig. 4 shows a characteristic precipitation event near Chongqing, China. For mudslide studies, those precipitation events separated by less than two dry days should be considered as one "super" rain event. Thus, unlike many previous studies (O'Gorman and Schneider 2009, and references therein), which count daily precipitation one day at a time, we count those extended super-rain events, defined as a somewhat continuous rainfall period nowhere separated by more than two consecutive dry days. For example, the precipitation time series in inset $\mathrm{A}$, if analyzed by the traditional method, would include 12 days with significant precipitation, covering four of the five bins. In our analysis, this is simply an extended rain event belonging to the category 5 precipitation (521-mm total precipitation) plus a moderate rainfall belonging to the $5-50-\mathrm{mm}$ category. In the following discussion, we frequently use a term "recurrence frequency" of a certain rainfall category. For a single model grid, it is simply defined as the total number of occurrences divided by the total number of years. For a regional area, it is the linear average among the model grids involved; that is, the total number of occurrences divided by the grid number and further divided by the total number of years.

For the 50-100-mm rainfall category, the Commonwealth Scientific and Industrial Research Organisation Mark version 3.0 (CSIRO Mk3.0) and L'Institut Pierre-Simon Laplace Coupled Model, version 4 (IPSL CM4), which have quite different and relatively coarse spatial resolutions $\left(1.88^{\circ}\right.$ latitude $\times 1.88^{\circ}$ longitude for CSIRO Mk 3.0 and $2.8^{\circ}$ latitude $\times 2.8^{\circ}$ longitude for IPSL CM4), simulated similar change patterns in precipitation recurrence frequency between 1971 and 2000 and between 2071 and 2100 (Fig. 4). Both indicate an apparent increase (i.e., one or more such rain events every two years) in region A. Rainfall of such an amount occurs less frequently in the Mediterranean climate regions (region B). The increase in frequency is generally less than one every five years. Other models under different nonmitigated scenarios vary only quantitatively and in geographical details. The rainfall morphological changes are a persistent feature across models. An online supplement contains an investigation of the rainfall morphological changes, according to extended rain events, classifying the rain events into five categories according to total rainfall amount (see Fig. S1 of the online supplement at http:// dx.doi.org//0.1175/2010BAMS3017.2).

Although both regions of interest show significant increases in extreme precipitation (see online supplement), the average annual precipitation changes are different. Precipitation over the Asian monsoon
Recurr. freq. changes $\left(\mathrm{yr}^{-1}\right)$ for category $50-100(\mathrm{~mm})$ precip.
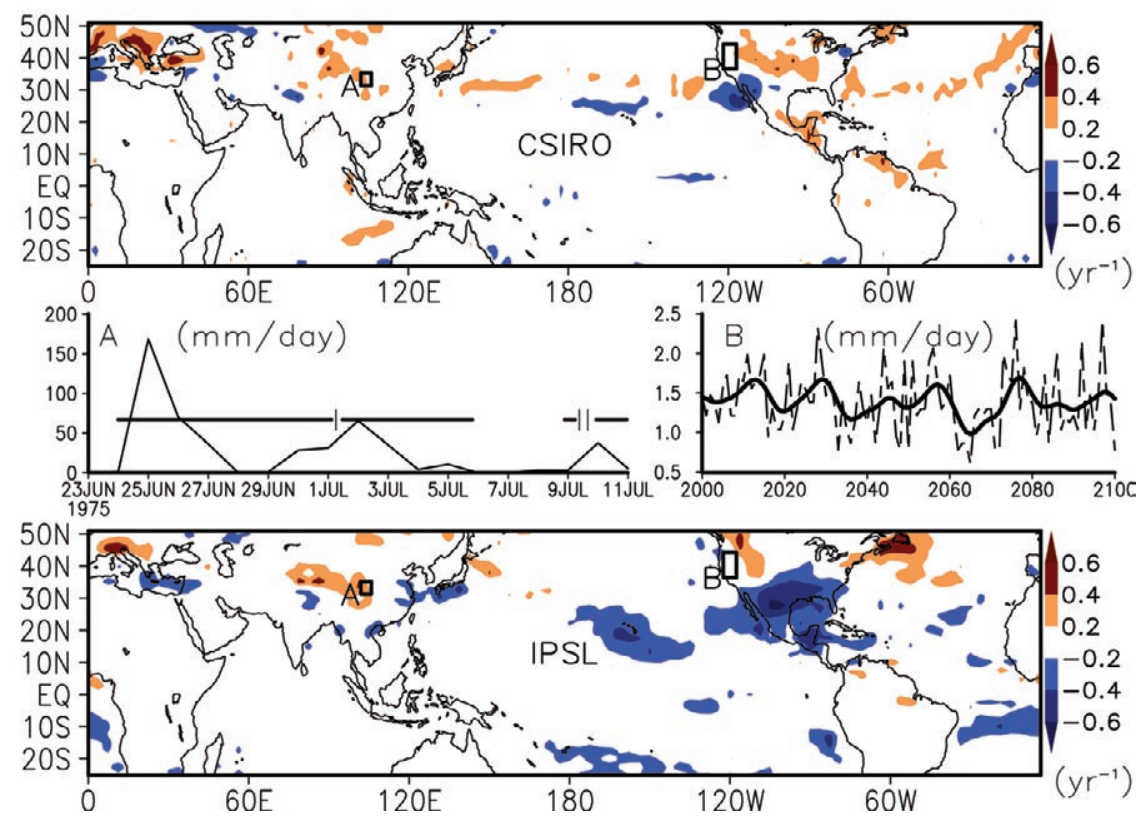

FIG. 4. The CSIRO Mk3.0 and IPSL CM4 simulated changes in precipitation (with rainfall amount between 50 and $100 \mathrm{~mm}$ ) occurrence frequency: 207I-2100 minus 197I-2000. For example, a value of -0.2 should be interpreted as one less such rain event every five years during the 207I-2100 period than during the 197I-2000 period. This amount category is extreme rainfall for a Mediterranean climate region. Inset $A$ is a characteristic rain event at region A. Inset B is the CCSM3-simulated precipitation trend over the Southern California region (area-averaged precipitation rate over the box-confined region near point B) under the SRES AIB scenario. The dashed line is the annual-mean time series of the area-weighted precipitation rate. The thick curve is a nonlinear trend estimate obtained by smoothing the corresponding annual series using a $2 \mathrm{l}$-term binomial filter. This helps to suppress short-term variabilities, such as EI Niño. 
region (point A) increases significantly, consistent with an increasing tropospheric specific humidity as pointed out by Allen and Ingram (2002). In fact, the increase in annual-mean precipitation over this region is mainly due to the shift toward heavier precipitation. The CCSM-simulated precipitation trend over the Southern California region under the SRES A1B scenario (see inset B of Fig. 4) counterintuitively indicates that total precipitation decreases by more than $0.1 \mathrm{~mm}^{\text {day }}{ }^{-1}$ on an annual basis. Storms become more intense but further apart in time, favoring a drought-flood bipolar temporal pattern as foreseen by Trenberth (1999). In addition to the eight CGCMs previously mentioned, we also examined the Geophysical Fluid Dynamics Laboratory Climate Model version 2.0 (GFDL CM2.0); Institute of Atmospheric Physics (IAP) Flexible Global Ocean-Atmosphere-Land System Model (FGOALS); the Centre National de Recherches Météorologiques Coupled Global Climate Model, version 3 (CNRM-CM3); and the Model for Interdisciplinary Research on Climate 3.2, highresolution version [MIROC3.2(hires)]. All 12 climate models show strong intermodel consistency for this finding.

So, a key component of understanding the impacts of human-induced global climate change on landslides is the likely nature of changes in extreme rainfall rather than the year-round rainfall total. It therefore is possible that the average annual rainfall for an area might decrease, but the occurrence of landslides increases if the rainfall arrives in more intense bursts. Liu et al. (2009) found that a $1^{\circ}$ increase in global temperature causes a $94 \%$ increase in the most intense rainfall events, with a decrease in moderate to light rainfall events. Indeed, the median rainfall increased from 4.3 to $18 \mathrm{~mm}^{\text {day }}{ }^{-1}$.

Projection of recurrence in storm-triggered landslides. To date, studies assessing potential landslides responses to twenty-first-century climate conditions have been lacking in physically based fully three-dimensional dynamic models. SEGMENT offers a unique opportunity for regional-scale assessment. The present consensus is that vegetation helps to prevent landslides (Dietrich and Perron 2006; Sidle 1992, and references therein). Through a series of sensitivity studies using the model, we concluded that precipitation-caused soil moisture direct loading to a slope is very small. However, soil moisture increments drastically change soil rheological properties. Because soil is saturated to a depth deeper than most roots, the preventative effects of the rooting system, as anticipated by Sidle (1992), actually diminishes. For all vegetated surfaces, canopy runoff is an effective preventative factor for landslides. For forest cover, biomass loading and wind stress on canopy are important factors for triggering slope instability, particularly when pore pressure builds up at the contact of sliding material and bedrock. Given that strong gales inevitably accompany severe storms, the wind stress on a canopy is an important but usually overlooked factor in dynamic landslides research.

Climate prediction is concerned with quantifying risks and probabilities (Allen and Ingram 2002). Although CGCMs are not able to project a specific storm's location and timing, the climatological trend in our regions of interest is reliable, given the broad intermodel consensus. For land areas with increased extreme precipitation, sensitivity studies should be performed with a dynamic landslide model driven by a range of rainfall amounts. Limited by space, in the following we describe a sensitivity study for the interested Southern California region.

Holdridge (1947) noted that same amount of mean annual precipitation amount may support vegetation of distinct appearance in continental and Mediterranean climates. The Mediterranean land covers have degraded from the original forest cover to chaparrals, xerophytic woodlands, and semiarid grasslands. They are highly susceptible to soil erosion if the vegetation cover is further removed. To project changes in landslides recurrence frequency, the dynamic model is integrated for an extended period of 200 years, driven by CCSM3-provided atmospheric conditions and current land cover. Figure 5 illustrates increases in major landslides (those involving at least $10^{4} \mathrm{~m}^{3}$ of sliding material). Fractional changes (which are changes of recurrence frequency compared with recurrence frequency extracted from the 1971-2000 period) are not used because there are regions not suffering landslides at present that will slide under a future climate. Under the present rainfall climatology, most regions are stable before seasonal precipitation reaches $250 \mathrm{~mm}$. Upon reaching this antecedent seasonal rainfall requirement, a rainfall event of at least a total of $33 \mathrm{~mm}$ is needed to trigger most of these landslides.

To examine the fractional changes in recurrence frequency (the average recurrence frequency during the 2050-2100 period compared with the 2000-50 period) within the three regional boxes in Fig. 3, we resampled the total number of major landslides with a $10-\mathrm{yr}$ window length and a 5-yr (window) slide interval. For some areas (e.g., east of San Bernardino), a more than 5\% increase is expected, with $95 \%$ confidence. For other CGCMs, we find that the increases in recurrence frequency scales 
with changes in area-mean surface air temperature. When scaled with warming, there is little intermodel scattering. Because the storms are more intense but farther apart for this area, droughts tend to be more severe and longer lasting, increasing the risk of forest fires. How fire removal of vegetation will increase landslide risk is an important but poorly studied natural hazards problem. SEGMENT parameterization may serve as a means of approaching this problem.

CONCLUSIONS. Natural hazards are an ever-present threat to human lives and infrastructure. The need for greater predictive capability has been identified as one of the 10 Grand Challenges in Earth Sciences (NRC 2008). As an effort toward the goal of reliable landslide mapping and warning system, we present a modeling system (SEGMENT) that systematically estimates the potential for landslides over a regional area, rather than for a single slope. The good performance of the model is attributable to the use of a new, fully three-dimensional modeling framework based on a newly proposed granular rheology and to the use of a land surface scheme that explicitly parameterizes the hydrological characteristics of macropores. Some requirements of the model, such as vegetation loading and root distribution in soils and weathered rocks, are not available even in modern geological maps. Applications of SEGMENT to other regions are limited primarily by a lack of high-resolution input datasets. However, the new concepts implemented in the model, if adopted by the community, may encourage the collection of such information in future surveys.

The future climate warming has influence on the occurrence of landslides caused by elevated water content in the ground. Changes in precipitation morphology is very relevant for storm-triggered landslides and subsequent desertification, because the root system of vegetation is accustomed to the current precipitation climatology and likely is not prepared for humaninduced changes in climate. Under the current relatively stable astronomical boundary conditions, there are natural "rhythms," whereas human induced changes are likely to transition significantly in one direction, leading to a state not experienced before by the existing terrestrial ecosystem. Microclimatic variations associated with slopes allow stands of an ecosystem type to exist far beyond their major zones of distribution (Chapin et al. 2002). These outliers act as important colonizing individuals during times of rapid climatic change. Destroying these outlier species (or transitional belts on Holdridge's chart) by landslide burial, accompanying extreme precipitation, may slow down ecosystem migration in accord with climate change.

ACKNOWLEDGMENTS. We thank the two anonymous BAMS reviewers, who improved the writing and quality of this paper significantly. We acknowledge the international modeling groups for providing their data for analysis and the Program for Climate Model Diagnosis and Intercomparison (PCMDI) for collecting and archiving the model data. Transient climate simulations under SRES A1B were obtained from the PCMDI Coupled Model Intercomparison Project (CMIP). These simulations were part of a series of simulations for the IPCC 2007 Fourth Assessment Report. We thank Drs. X. Xiang, J. Liao, and Y. Hong (OU) for providing some technical assistance. This study was partly supported by the NSF award AGS-0937400 which was awarded to Rong $\mathrm{Fu}$, coauthor of this paper.

\section{REFERENCES}

Allen, M., and W. Ingram, 2002: Constraints on future changes in climate and the hydrologic cycle. Nature, 419, 224-232. 
Baum, R., W. Savage, and J. Godt, 2008: TRIGRS-A Fortran program for transient rainfall infiltration and grid-based regional slope-stability analysis, version 2.0. U.S. Geological Survey Open-File Rep., 75 pp.

Bhandari, R., 1988: Special lecture on some practical lessons in the investigation and field monitoring of landslides. Landslides: Proceedings of the 5th International Symposium on Landslides, C. Bonnard, Ed., Vol. 2, A. A. Balkema, 1435-1457.

Caine, N., 1980: The rainfall intensity-duration control of shallow landslides and debris flows. Geogr. Ann., 62A, 23-27.

Cannon, S. H., and S. Ellen, 1985: Rainfall conditions for abundant debris avalanches, San Francisco Bay region, California. Calif. Geol., 38, 267-272.

— flow from a hazards perspective. Debris-Flow Hazards and Related Phenomena, M. Jacob and O. Hungr, Eds., Springer-Praxis, 321-344.

_, J. Michael, J. Gartner, and J. Gleason, 2003: Assessment of potential debris-flow peak discharges from basins burned by the 2002 Missionary Ridge Fire, Colorado. U.S. Geological Survey Open-File Rep. 03-332, 8 pp.

Casadei, M., W. Dietrich, and N. Miller, 2003: Testing a model for predicting the timing and location of shallow landslide initiation in soil-mantled landscapes. Earth Surf. Processes Landforms, 28, 925-950.

Chapin, F., III, P. Matson, and H. Mooney, 2002: Principles of Terrestrial Ecosystem Ecology. Springer, 436 pp.

Chen, M., R. Dickinson, X. Zeng, and A. Hahmann, 1996: Comparison of precipitation observed over the continental United States to that simulated by a climate model. J. Climate, 9, 2223-2249.

Collins, W. D., and Coauthors 2006: The Community Climate System Model version 3 (CCSM3). J. Climate, 19, 2122-2143.

Costa, J. E., 1984: Physical geography of debris flows. Developments and Applications in Geomorphology, J. E. Costa and P. J. Fleisher, Eds., Springer Verlag, 268-317.

Dai, A., F. Giorgi, and K. Trenberth, 1999: Observed and model simulated precipitation diurnal cycles over the contiguous United States. J. Geophys. Res., 104, 6377-6402.

Dietrich, W., and J. Perron, 2006: The search for a topographic signature of life. Nature, 439, 411-418.

Godt, J. W., R. L. Baum, and A. F. Chleborad, 2006: Rainfall characteristics for shallow landsliding in Seattle, Washington, USA. Earth Surf. Processes Landforms, 31, 97-110.
Groisman, P. Ya., R. Knight, T. Karl, D. Easterling, B. Sun, and J. Lawrimore, 2004: Contemporary changes of the hydrological cycle over the contiguous United States: Trends derived from in situ observations. J. Hydrometeor., 5, 64-85.

Hansen, J., M. Sato, R. Ruedy, K. Lo, D. Lea, and M. Medina-Elizade, 2006: Global temperature change. Proc. Natl. Acad. Sci. USA, 103, 14 288-14 293.

Holdridge, L., 1947: Determination of world plant formations from simple climatic data. Science, 105, 367-368.

Hong, Y., and R. F. Adler, 2008: Predicting landslide spatiotemporal distribution: Integrating landslide susceptibility zoning techniques and real-time satellite rainfall estimates. Int. J. Sediment Res., 23, 249-257.

IPCC, 2007: Global climate projections. Climate Change 2007: The Physical Science Basis. Contribution of Working Group I to the Fourth Assessment Report of the Intergovernmental Panel on Climate Change, Solomon, S., D. Qin, M. Manning, Z. Chen, M. Marquis, K.B. Averyt, M. Tignor and H.L. Miller, Eds., Cambridge University Press, 747-846. [Available online at www. ipcc.ch/publications_and_data/publications_ipcc_ fourth_assessment_report_wg1_report_the_physical_science_basis.htm.]

Iverson, R., 1997: The physics of debris flows. Rev. Geophys., 35, 245-296.

- 2000: Landslide triggering by rain infiltration. Water Resour. Res., 36, 1897-1910.

Karl, T., and K. Trenberth, 2003: Modern global climate change. Science, 302, 1719-1723.

Kharin, V., and F. Zwiers, 2005: Estimating extremes in transient climate change simulations. J. Climate, 18, 1156-1173.

Liu, S. C., C. Fu, C.-J. Shiu, J.-P. Chen, and F. Wu, 2009: Temperature dependence of global precipitation extremes. Geophys. Res. Lett., 36, L17702, doi:10.1029/2009GL040218.

Meehl, G., and C. Tebaldi, 2004: More intense, more frequent, and longer lasting heat waves in the $21 \mathrm{st}$ century. Science, 305, 994-997.

Nakicenovic, N., and R. Swart, Eds., 2000: Special Report on Emissions Scenarios. Cambridge University Press, $612 \mathrm{pp}$.

NRC, 2002: Abrupt Climate Change: Inevitable Surprises. National Academy Press, 230 pp.

- , 2008: Origin and Evolution of Earth: Research Questions for a Changing Planet. National Academy Press, 137 pp.

O'Gorman, P., and T. Schneider, 2009: The physical basis for increases in precipitation extremes in simulations of 21st century climate change. Proc. Natl. Acad. Sci. USA, 106, 14 773-14 777. 
Peterson, T., and M. Manton, 2008: Monitoring changes in climate extremes. Bull. Amer. Meteor. Soc., 89, 1266-1271.

Ren, D., L. Leslie, and D. Karoly, 2008: Mudslide risk analysis using a new constitutive relationship for granular flow. Earth Interactions, 12. [Available online at http://EarthInteractions.org.]

—, J. Wang, R. Fu, D. Karoly, Y. Hong, L. M. Leslie, C. Fu, and G. Huang, 2009: Mudslide-caused ecosystem degradation following Wenchuan earthquake 2008. Geophys. Res. Lett., 36, L05401, doi:10.1029/2008GL036702.

—, L. M. Leslie, R. Fu, R. Dickinson, and X. Xin, 2010: A storm-triggered landslide monitoring and prediction system: Formulation and case study. Earth Interactions, 14. [Available online at http:// EarthInteractions.org.]

—, R. Fu, L. M. Leslie, and R. E. Dickinson, 2011: Modeling the mudslide aftermath of the 2007 Southern California wildfires. Nat. Hazards, in press.

Restrepo, P., and Coauthors 2008: Joint NOAA/NWS/ USGS prototype debris flow warning system for recently burned areas in Southern California. Bull. Amer. Meteor. Soc., 89, 1845-1851.

Schulz, W. H., J. W. Kean, and G. Wang, 2009: Landslide movement in southwest Colorado triggered by atmospheric tides. Nat. Geosci., 2, 863-866.

Schuster, R., and L. Highland, 2001: Socioeconomic and environmental impacts of landslides in the Western Hemisphere. U.S. Geological Survey Open-File Rep. 01-0276, 47 pp. [Available online at http://pubs.usgs. gov/of/2001/ofr-01-0276/.]

Semenov, V., and L. Bengtsson, 2002: Secular trends in daily precipitation characteristic greenhouse gas simulation with a coupled AOGCM. Climate Dyn., 19, 123-140.
Sidle, R., 1992: A theoretical model of the effects of timber harvesting on slope stability. Water Resour. Res., 28, 1897-1910.

Sirangelo, B., and P. Versace, 1996: A real time forecasting model for landslides triggered by rainfall. Meccanica, 31, 73-85.

Solomon, S., D. Qin, M. Manning, M. Marquis, K. Averyt, M. M. B. Tignor, H. L. Miller Jr., and Z. Chen, Eds., 2007: Climate Change 2007: The Physical Science Basis. Cambridge University Press, 996 pp

Stone, R., 2009: Wenchuan earthquake, a deeply scarred land. Science, 324, 713-714.

Trenberth, K., 1999: Conceptual framework for changes of extremes of the hydrological cycle with climate change. Climatic Change, 42, 327-339.

van Asch, T. W. J., J.-P. Malet, L. P. H. van Beek, and D. Amitrano, 2007: Techniques, issues and advances in numerical modelling of landslide hazard. Bull. Soc. Geol. Fr., 178, 65-88.

White, M. A., N. S. Diffenbaugh, G. V. Jones, J. S. Pal, and F. Giorgi, 2006: Extreme heat reductions and shifts United States premium wine production in the 21st century. Proc. Natl. Acad. Sci. USA, 103, 11 217-11 222.

Wooten, R. M., K. A. Gillon, A. Witt, R. Latham, T. Douglas, J. Bauer, S. Fuemmeler, and L. Lee, 2008: Geologic, geomorphic, and meteorological aspects of debris flows triggered by Hurricanes Frances and Ivan during September 2004 in the southern Appalachian Mountains of Macon County, North Carolina (southeastern USA). Landslides, 5, 31-44.

Zwiers, F. W., and V. V. Kharin, 1998: Changes in the extremes of the climate simulated by CCC GCM2 under CO2 doubling. J. Climate, 11, 2200-2222. 